\title{
Economic valuation of natural pest control of the summer grain aphid in wheat in South East England
}

Article

Accepted Version

Creative Commons: Attribution-Noncommercial-No Derivative Works 4.0

Zhang, H., Garratt, M. P. D., Bailey, A., Potts, S. G. and Breeze, T. (2018) Economic valuation of natural pest control of the summer grain aphid in wheat in South East England.

Ecosystem Services, 30 (A). pp. 149-157. ISSN 2212-0416 doi: https://doi.org/10.1016/j.ecoser.2018.02.019 Available at https://centaur.reading.ac.uk/76197/

It is advisable to refer to the publisher's version if you intend to cite from the work. See Guidance on citing.

To link to this article DOI: http://dx.doi.org/10.1016/j.ecoser.2018.02.019

Publisher: Elsevier

All outputs in CentAUR are protected by Intellectual Property Rights law, including copyright law. Copyright and IPR is retained by the creators or other copyright holders. Terms and conditions for use of this material are defined in the End User Agreement.

www.reading.ac.uk/centaur 
Central Archive at the University of Reading

Reading's research outputs online 


\title{
Full title: Economic valuation of natural pest control of the summer grain aphid in wheat in South East England
}

\section{Short title: Valuing natural pest control in wheat-grain aphid system}

\author{
Han Zhang, ${ }^{a}$; Michael P.D. Garratt ${ }^{a}$; Alison Bailey ${ }^{b}$; Simon G. Potts ${ }^{a}$; Tom Breeze \\ ${ }^{a}$ Centre for Agri-Environmental Research, School of Agriculture, Policy and Development, University \\ of Reading, Reading, Berkshire RG6 6AR, UK \\ ${ }^{b}$ Land Management and Systems, Faculty of Agribusiness and Commerce, Lincoln University, Lincoln \\ 7647, Christchurch, New Zealand \\ * Corresponding author.
}

Email address: mzresearch99@gmail.com (H. Zhang), m.p.garratt@reading.ac.uk (M.P.D. Garratt), Alison.Bailey@lincoln.ac.nz (A. Bailey),s.g.potts@reading.ac.uk (S.G. Potts), t.d.breeze@reading.ac.uk (T. Breeze).

\begin{abstract}
Wheat (Triticum spp.) is the most important arable crop grown in the UK, and the grain aphid (Sitobion avenae) is one of the key pests of this crop. Natural enemies could help suppress grain aphid and reduce unnecessary insecticide inputs, but few studies have estimated the economic value of natural pest control in this crop-pest system, which could help inform effective integrated pest management strategies. Based on a natural enemy exclusion experiment carried out in South East England, this study used an economic surplus model to estimate the value of predators and parasitoids to control summer grain aphid in wheat in this region. Incorporating three levels of spray intensity and three levels of pest infestation, the annual economic value of natural pest control
\end{abstract}


service was conservatively estimated to be f0-2.3 Million. Under the medium pest infestation level, a $10 \%$ increase in the proportion of wheat fields using economic threshold-based spray method would increase this value by $23 \%$ ( $f 0.4$ Million). $71 \%$ of the value would benefit wheat growers. A potential rise in insecticide costs due to resistance development would also enhance the value of natural pest control. These findings support growing efforts from policy-makers to promote this ecosystem service in agriculture.

\section{Key words}

Natural pest control service; economic surplus valuation; Sitobion avenae; Triticum spp.; integrated pest management; ecosystem services 


\section{Introduction}

Wheat (Triticum spp.) is the most widely cultivated crop in the UK, with 2 million ha planted annually from 2010 to 2014 , representing $42 \%$ of the total national arable cropping area and generating $f 2$ billion in sales annually (DEFRA, 2015a, 2014). The grain aphid, Sitobion avenae Fabricius (Hemiptera: Aphididae), is one of the main insect pests in UK wheat production (Foster et al., 2014), acting as a potential vector of the barley yellow dwarf virus to the young seedlings sown during the autumn period and causing direct feeding damage through leaves and ears in the summer (Dewar et al., 2016). Indirect crop damage caused by the summer grain aphid is the secretion of honeydew during feeding, which provides a medium for sooty moulds that reduce the photosynthetic rate (Larsson, 2005).

The dominant insecticides applied in wheat to control summer grain aphid are pyrethroid sprays. From 2010 to 2014, an average of 1.6 million ha of UK wheat was treated with pyrethroids annually, representing 92\% of total insecticidal spray area for this crop (Garthwaite et al. 2010, 2012, 2014). However, since 2011, pyrethroid resistance has developed in the UK grain aphid (AHDB, 2015; Foster et al., 2014). An alternative spray for aphid control has been pirimicarb (1.5\% of total insecticidal spray area for wheat) (Garthwaite et al. 2010, 2012, 2014), however, its authorisations are set to end in July 2017 (AHDB, 2016a; Dewar et al., 2016). These factors have caused concerns for the future of effective grain aphid control in UK wheat.

An alternative control mechanism for grain aphid infestation is provided by natural enemies present in the wheat fields, including predators (e.g., Carabidae), parasitoids (e.g., Aphidiinae), and pathogens (e.g., Entomophthorales). Many studies have demonstrated their importance for suppressing grain aphid damage in wheat production (Plantegenest et al., 2001; Safarzoda et al., 2014; Schmidt et al., 2003; Thies et al., 2011). Beyond direct pest control, the contributions of natural pest control include: reducing the rate of development of insecticide resistance in pests (Lefebvre et al., 2015; Liu et al., 2014), providing consumers with potentially healthier food 
containing fewer chemical residues (Baker et al., 2002; Florax et al., 2005), and reducing negative effects of insecticides on other ecosystem services (e.g., pollination, see Potts et al. 2016).

The effectiveness of natural pest control is influenced by various factors: farm management (Holland, 2004), landscape structure (Martin et al., 2013), weather and climate change (Ewald et al., 2015), etc. Foremost, numerous studies have demonstrated that insecticides negatively affect the development and pest control abilities of natural enemies in croplands by killing or weakening nontarget species (Geiger et al., 2010; Roubos et al., 2014). Indeed, there have been policy and research interests in encouraging a reduction in the intensity of insecticide application, particularly by using the economic threshold method pioneered by Stern et al., (1959). This method encourages farmers to use insecticides as a complement to natural pest control, treating crops only when it is necessary to prevent an increasing pest density from reaching the economic injury level (EIL), where the cost of control equals the perceived value of crop damage (Pedigo et al., 1986; Stern et al., 1959).

By monitoring grain aphid densities in summer and comparing the subsequent yield responses in 49 wheat fields across England and Wales, George and Gair (1979) advised that the economic threshold for UK grain aphid in summer is five aphids/tiller. This threshold level was further validated by Oakley and Walters (1994), and is now recommended for UK wheat growers to follow when treating summer grain aphid infestations (Dewar et al., 2016; Ramsden et al., 2017). However, there remains little information on the extent of benefits that this method can have in enhancing natural pest control service for UK wheat production.

Estimating the economic benefits of an ecosystem service has been suggested as a method to quantify its contribution to human welfare, encourage farmers to implement a more sustainable pest management approach, and guide policy makers in supporting relevant conservation programs (Braat and de Groot, 2012; Schaefer et al., 2015). Some attempts have been made to estimate the monetary values of natural pest control service (see Table 1 in Naranjo et al. 2015 as a summary). It is difficult to compare the values among economic studies, because of the often significant 
differences in study locations, trophic relationships, input costs, data used, and modelling techniques. However, few evaluations have been conducted on the wheat-grain aphid system (Porter et al., 2009), and to our knowledge, none on any crop-pest system within the UK context.

By expanding upon the economic surplus model developed by Letourneau et al. (2015), this study estimates the economic value of natural pest control of the summer grain aphid damage in UK wheat, while accounting for the influence of different intensities of insecticide input and levels of pest infestation. In particular, the potential contribution of the economic threshold-based method towards the value of natural pest control is analysed. By conducting a set of sensitivity analyses, this study also quantifies the potential variation in the value from the uncertainties in the price elasticities of supply and demand, and the insecticide input costs. This study focuses on the summer grain aphid control by the related predators and parasitoids in the South East England. However, the model could potentially be used for other regions and crop-pest systems.

\section{Materials and Methods}

\subsection{Overview of economic surplus method}

The economic surplus method is commonly used in economics to estimate the change in benefits and costs brought by a change in technology in a market setting (Alston et al., 1998). It is measured as the sum of consumer surplus $(\Delta C S$, benefits that consumers would receive when the market price that they pay for a product is lower than the highest price they are willing to pay) and producer surplus ( $\triangle \mathrm{PS}$, benefits that producers receive when they sell a product at a higher price than the cost of producing it). Assume Fig. 1 represents the wheat market in South East England. The demand curve (Demand) denotes the relationship between wheat price and quantity that consumers are willing and able to purchase. The supply curve (Supply 1) is the relationship between product price and quantity that farmers are willing to produce. The intercept between the two curves represents 
an equilibrium point where the market price is set $\left(P_{0}\right)$, with related wheat quantities produced $\left(Q_{0}\right)$. Consumer surplus is represented by the area $(A+B+C)$, and producer surplus $(D+E)$.

Hypothetically, if there is an absence of natural enemies of the summer grain aphid in the wheat fields in South East England (i.e., natural pest control is at the minimum level), crop damage from grain aphid would be likely to occur (Östman et al., 2003), resulting in lower yields or increased insecticide input. Either of these two changes would increase the incremental cost of crop production, leading to a leftward shift of the supply curve (Supply 2 ), and a higher market price $\left(\mathrm{P}_{1}\right)$. Thus the economic surplus will fall $(A+B+D)$ and the difference in economic surplus with and without natural pest control can be identified $(\mathrm{C}+\mathrm{E})$, capturing the value of this ecosystem service (Alston et al., 1998; Letourneau et al., 2015).

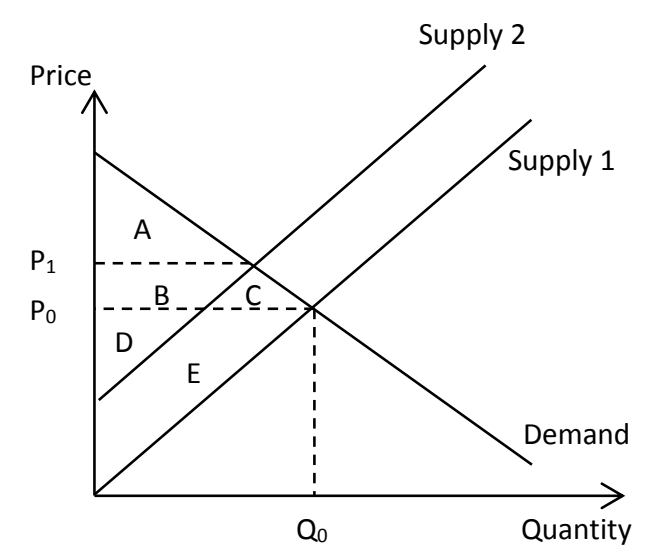

Fig 1. Framework of wheat market in South East England and the related measurement of economic surplus

\subsection{Insecticide intensity and pest infestation levels}

This study incorporated three levels of insecticidal application intensity of foliar sprays in the model: i) no-spray, where no foliar sprays are used to control grain aphid in the summer; ii) economic threshold-based spray (ET), where insecticides are applied according to the economic threshold of grain aphid (five aphids/tiller) in the fields (George and Gair, 1979; Oakley and Walters, 1994); and, 
iii) preventive spray, where foliar sprays are always applied in the summer to prevent crop damage from grain aphid.

It is assumed that ET and preventive sprays can successfully control grain aphid damage to the extent that yield will not be influenced (Letourneau et al., 2015; Song and Swinton, 2009). Thus, an absence of natural enemies could result in a yield reduction in no-spray fields, and insecticide increase in ET fields, but would not influence preventive spray fields. The potential influence on the supply shift (From Supply 1 to Supply 2 in Fig. 1 , denoted as $K$ ) by exclusion of natural pest control in the wheat fields can therefore be derived as follows (Eq. 1). It is estimated as a weighted average influence from the potential yield reduction in the no-spray fields, and insecticide increase in the ET fields. For a detailed model refer to Letourneau et al., 2015 (p217, Eq. 3).

$K=\sigma_{\text {no-spray }} I_{\text {no-spray }}+\sigma_{E T} I_{E T}$

where $\mathrm{K}$ denotes the supply shift parameter, $\sigma_{\text {no-spray }}$ and $\sigma_{\mathrm{ET}}$ denote the percentage of wheat fields that use no-spray and ET methods respectively, and $I_{\text {no-spray }}$ and $I_{E T}$ denote the influence on the supply shift by an exclusion of natural pest control in the no-spray and ET fields respectively.

The influence on the supply shift also depends upon the level of pest infestation in the fields, which will fluctuate naturally. Therefore, expanding upon Letourneau et al. (2015), three pest infestation levels were used to capture this uncertainty (Fig. 2):

1. Low infestation level: under this level, grain aphid density would be lower than the economic threshold (five aphids/tiller) even with an absence of natural enemies in the fields. Thus, no subsequent yield reduction would occur in the no-spray fields, and no related increase of insecticidal sprays would be needed for ET fields. In this case $\mathrm{K}=0$.

2. Medium infestation level: under this level, grain aphid density would be lower than the economic threshold if natural enemies are present in the fields, but would be higher if natural enemies are 
absent. Thus, without natural enemies, related yield reduction would occur in the no-spray fields, and insecticide costs would be increased in ET fields. In this case $K=\sigma_{\text {no-spray }} I_{\text {no-spray }}+\sigma_{E T} l_{E T}$.

3. High infestation level: under this level, grain aphid density would exceed the economic threshold even with natural enemies in the fields. However, compared with the no-spray fields where natural enemies are present, those without such pest control mechanism would harvest less wheat. As for the potential insecticide input change in the ET fields, because the average annual number of insecticidal spray rounds applied to UK wheat (2010 to 2014) was one (Garthwaite et al. 2010, 2012, 2014), we assumed that when aphid density exceeds the economic threshold, one spray round at the recommended dose would be sufficient to control the pest. Thus, under this level, insecticide input would remain the same (one spray round) regardless of the level of natural pest control in the wheat fields. $\mathrm{K}=\sigma_{\text {no-spray }} I_{\text {no-spray. }}$.

(I) Peak grain aphid densities

(L)

(M)

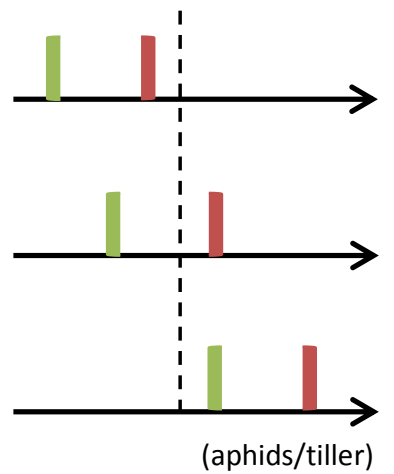

(II) No-spray fields

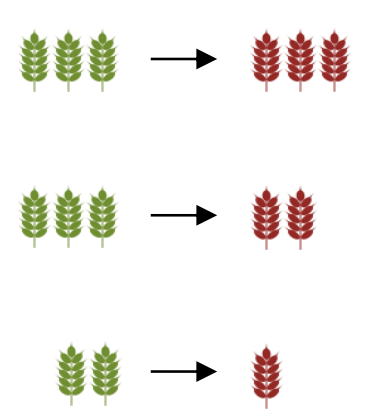

(III) ET fields

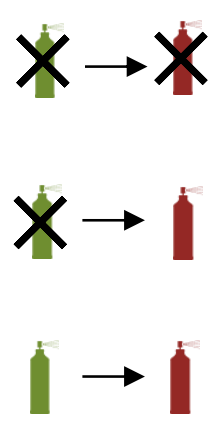

Fig 2. Conceptual model of (I) peak grain aphid densities (aphids/tiller), (II) the related levels of crop yields in the no-spray wheat fields, and (III) the related levels of insecticidal spray inputs in the economic thresholdbased (ET) wheat fields, under the (L) low, (M) medium, and (H) high pest infestation levels in South East England. Colour green and red denote the presence and absence of related natural enemies respectively. In the column I: the dotted line denotes the action threshold of grain aphid control; the coloured solid lines denote the amount of peak grain aphid densities; the distance between the green and red lines represents the difference of the peak grain aphid densities with and without natural pest control in the wheat fields. In the columns II and III, the amount of wheat grain and spray symbols represent a rough measure of the level of 
crop yields and spray inputs respectively. In column III, the black cross symbol denotes that no spray is required.

Economic surplus ( $\triangle \mathrm{ES}$ ) is estimated as follows (Eq. 2-5) (Letourneau et al., 2015):

$Z=K \varepsilon /(\varepsilon+\eta)$

$\Delta C S=Z Q_{0} P_{0}(1+0.5 Z \eta)$

$\Delta P S=Q_{0} P_{0}(K-Z)(1+0.5 Z \eta)$

$\Delta E S=\triangle C S+\triangle P S$

where $\eta$ denotes the absolute value of the price elasticity of demand for wheat in the South East England, and $\varepsilon$ the price elasticity of supply. $\triangle \mathrm{CS}$ consumer surplus, and $\triangle \mathrm{PS}$ producer surplus. The price elasticity of demand is a measure of the responsiveness of the quantity demanded by consumers of that good to changes in its price. It is defined as the percentage change in quantity demanded that results from a one percent change in the price. The demand for a good is elastic relative to the price if the absolute value of demand elasticity is greater than one, and inelastic if less than one. The price elasticity of supply is the analogous measure on the producers' side.

\subsection{Modelling of Ino-spray}

Data for the analyses of yield response changes with and without natural enemies in no-spray fields ( $I_{\text {no-spray }}$ in Eq. 1) was derived from a field experiment conducted as part of the European Union (EU) funded LIBERATION (Linking farmland biodiversity to ecosystem services for effective eco-functional intensification, www.fp7liberation.eu) project. 16 winter wheat fields (minimum distance of $1 \mathrm{~km}$ apart) were selected in Oxfordshire and Berkshire, in South East England. Fields were conventionally 
managed, of varying size, and were selected along a geographical and local landscape context gradient so they captured the variability found in arable fields in this region. At the edge of each field site, an experimental treatment plot of $15 \times 14 \mathrm{~m}$ was established. All plots were managed conventionally with application of plant protection products as normal except that they received no foliar application of insecticide.

Levels of aphid control by natural enemies in each of the plots were measured using cage experiments, using a methodology adapted from Rusch et al. (2013). At around GS50 BBCH, approximately 50-100 grain aphids were introduced to two experimental areas within each plot. The aphid population was left to establish for 10 days before one was randomly selected for an open treatment and one had a field cage placed over the aphid population to exclude both aerial and ground dwelling natural enemies. Cages with $5 \times 5 \mathrm{~mm}$ plastic mesh net $(30 \mathrm{~cm}$ diameter and $100 \mathrm{~cm}$ high) and a solid metal cylinder base were dug $10 \mathrm{~cm}$ into the soil to prevent ground-dwelling predators from entering the cages. To prevent flying predators, cages were sprayed with sticky glue. An initial count of aphids in the open and caged area was made at cage establishment. After 5 days the plots were again visited and a second aphid count was carried out.

Expected wheat yield loss response due to summer grain aphid damage (feeding and honeydew) was taken from a study involving 161 field experiments with randomized complete block designs across South Sweden (Larsson, 2005):

$Y=4.5 \ln (A)-5.5\left(R^{2}=0.97\right)$

where $A$ is the number of peak grain aphids per tiller, and $Y$ is the percentage yield loss (\%) due to aphid damage in winter wheat. Based on Eq. 6, the economic injury level (EIL) of grain aphid in South East England is 4.6 aphids/tiller (taking into account the average wheat yield, perceived yield loss, wheat price, and insecticide input cost; Table 2.1 and 2.2), which rounds up to five aphids/ tiller, the same as the economic threshold. Because of the quick knockdown effects of pyrethroids (Briggs et 
al., 1974; Elliott et al., 1978), we assume that when grain aphid reaches the threshold level, pyrethroid sprays would immediately take effects to prevent subsequent yield loss from this pest.

To use Eq. 6 to estimate the relative yield response with and without the contribution of natural enemies in the fields ( $I_{\text {no-spray }}$ in Eq. 1 ), the relationship between the peak aphid densities with and without natural enemies was needed. Data collected from the cage experiments were used to estimate this relationship. It was assumed that the relationship at the second aphid count in the cage experiments represented the situation at the peak aphid dates. It was also assumed that this experiment represents a normal level of natural pest control in South East England, and that pest densities can always be reduced by natural enemies:

$A_{\text {without }}=1.96 A_{\text {with }}+1.65\left(R^{2}=0.58\right)$

where $A_{\text {with }}$ denotes the peak aphid density (aphids/tiller) with natural enemies in the fields, $A_{\text {without }}$ denotes the peak aphid density without natural enemies.

From Eq. 6 and Eq. 7, the estimated peak aphid densities (A) and percentage yield loss (Y) in relation to a change in natural enemies were displayed (Table 1). It showed that with a normal level of natural pest control in the wheat fields: low pest infestation level is when the peak aphid/tiller is zero or one, medium level is when peak aphid/tiller reached two to four, and high level is when peak aphid/tiller is five or higher. Because grain aphid density in England normally lies below five (Dewar et al., 2016; Holland and Oakley, 2007), we only included five and six aphids/tiller in the high infestation scenario. 


\begin{tabular}{cccc}
\hline $\begin{array}{c}\text { Peak grain aphid densities } \\
\text { (number/tiller) }\end{array}$ & \multicolumn{2}{c}{ Percentage yield losses (\%) } \\
\hline Without NE $^{1}$ & With NE & Without NE & With NE \\
\hline 2 & 0 & 0 & 0 \\
4 & 1 & 0 & 0 \\
6 & 2 & 2 & 0 \\
8 & 3 & 4 & 0 \\
9 & 4 & 5 & $0^{2}$ \\
11 & 5 & 6 & 2 \\
13 & 6 & 6 & 3 \\
\hline
\end{tabular}

Table 1. Estimated peak aphid densities and yield reductions in relation to a change in natural enemies in the wheat fields in South East England.

Note: $1 . \mathrm{NE}=$ natural enemies; 2 . this value amounts to $<1 \%$ so is treated as no damage.

\subsection{Derivation of indicator values}

For each pest infestation level, we estimated an average annual economic surplus value of natural pest control of the summer grain aphid in South East England for the years 2010 to 2014 using a number of indictors (see Table 2 ). Wheat crop prices ( $f / h a$ ) were inflated according to the Consumer Price Index (CPI), taking 2014 as a base year (ONS, 2016). For the related insecticide increase (IET in Eq. 1), data from Nix (2010-2014) and ABC (2010-2014) were combined to take into account price changes in chemical, labour, machinery and fuel costs. To estimate the proportion of no-spray wheat fields in South East England ( $\sigma_{\text {no-spray }}$ in Eq. 1), the average percentage of organic wheat fields in England for the past five years (2010 to 2014) was used as an estimation (DEFRA, 2016a). To estimate the proportion of ET fields ( $\sigma_{\mathrm{ET}}$ in Eq. 1), we assumed that the average percentage of wheat fields without insecticide sprays from 2010 to 2014 represented the sum of no-spray and ET fields, thus achieving estimates for the proportion of ET fields (Garthwaite et al. 2010, 2012, 2014). Because little regional or national price elasticity ( $\varepsilon$ and $\eta$ in Eq. 2 ) information was available for UK wheat production, estimations for the EU15 (the 15 member countries, including UK, in the 
European Union prior to the accession of ten candidate countries on 1 May 2004) were used (FAPRI, 2016; Haile et al., 2015).

\begin{tabular}{|c|c|c|c|c|c|}
\hline Region: South East England & 2010 & 2011 & 2012 & 2013 & 2014 \\
\hline Wheat areas (1000 ha) ${ }^{1}$ & 240 & 243 & 248 & 197 & 237 \\
\hline Wheat yields $(\mathrm{t} / \mathrm{ha})^{1}$ & 8 & 8 & 7 & 7 & 9 \\
\hline Wheat quantities (Million $\mathrm{t})^{1}$ & 1.9 & 2.0 & 1.7 & 1.4 & 2.1 \\
\hline Wheat prices $(\mathrm{f} / \mathrm{t})^{2}$ & 169 & 173 & 209 & 164 & 133 \\
\hline Insecticide input $(f / h a)^{3}$ & 20 & 21 & 16 & 16 & 18 \\
\hline Proportion of no-spray fields $(\%)^{4}$ & 0.8 & 0.8 & 0.8 & 0.8 & 0.8 \\
\hline Proportion of ET fields $(\%)^{5}$ & 37 & 37 & 37 & 37 & 37 \\
\hline Absolute value of demand elasticity ${ }^{6}$ & 0.3 & 0.3 & 0.3 & 0.3 & 0.3 \\
\hline Supply elasticity ${ }^{6}$ & 0.12 & 0.12 & 0.12 & 0.12 & 0.12 \\
\hline
\end{tabular}

\section{Table 2. Indicators of economic surplus model}

Note: 1. From DEFRA (2015b); 2. Average ex-farm prices between milling and feeding wheat in the South East England (AHDB, 2016b), inflated using 2014 as base year (ONS, 2016); 3. Estimated from Nix (2010-2014) and ABC (2010-2014), inflated using 2014 as base year (ONS, 2016); 4. Estimated from DEFRA (2016d); 5. Estimated from Garthwaite et al. (2010, 2012, 2014), and ET = economic threshold-based spray; 6. Estimated from Haile et al. (2015) and FAPRI (2016).

\section{Results}

The annual average economic benefits provided by the natural pest control of summer grain aphid in wheat in South East England (2010-2014, with 2014 as base year) were: $£ 0$ under the low pest infestation level, $£ 2.3$ Million (standard deviation $£ 0.4$ Million) under the medium level, and $£ 0.8$ Million (standard deviation f0.1 Million) under the high level (Fig. 3). 


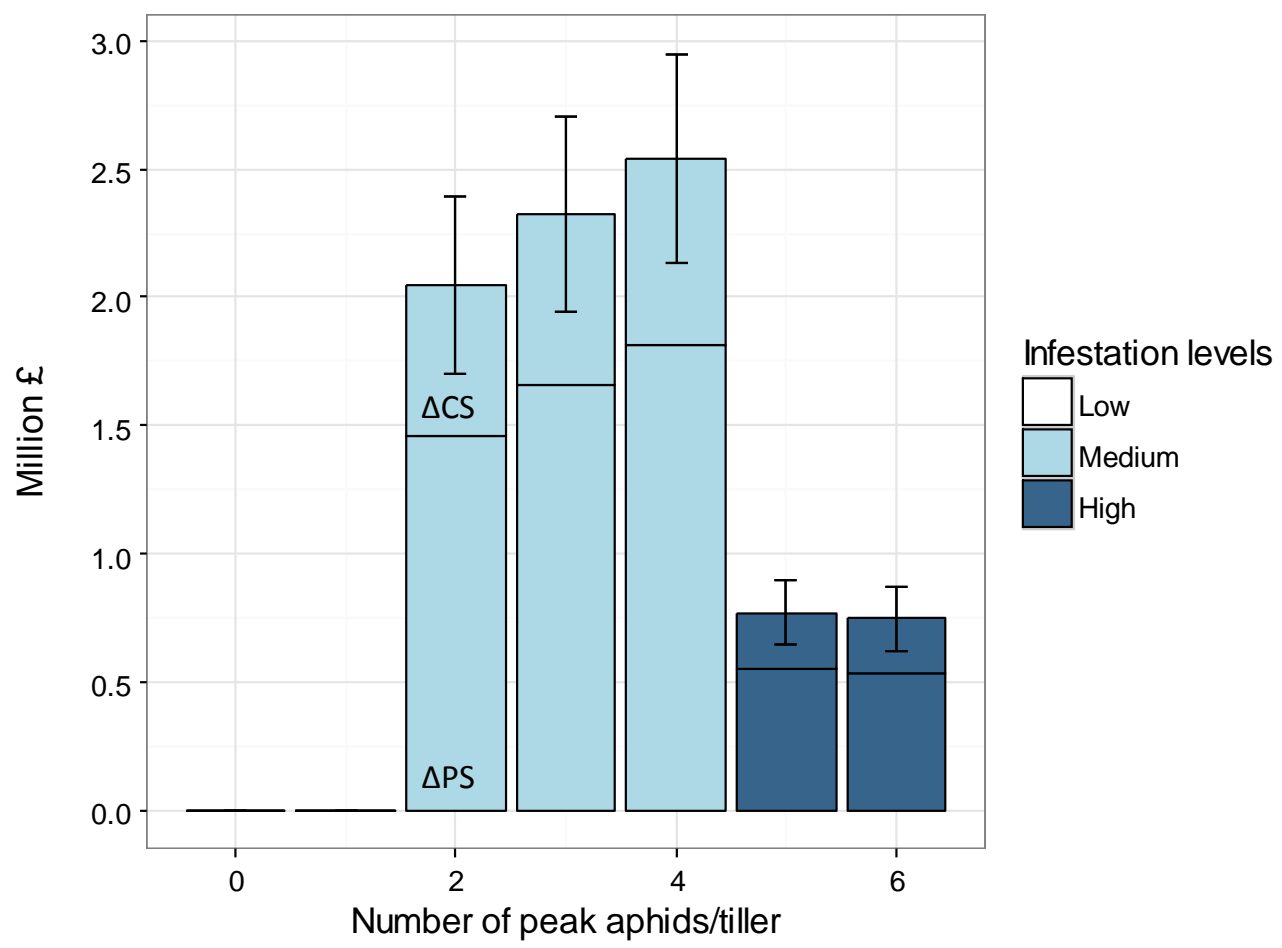

Fig 3. Economic surplus values of natural pest control for summer grain aphid in wheat in South East England. The blue bars denote average economic surplus (Million f) from 2010 to 2014 (2014 as base year), and the error bars denote related standard deviations. For each bar, the section above the horizontal line denotes consumer surplus $(\triangle C S)$, and below producer surplus $(\triangle P S)$. There were no values for the low infestation level (where pest densities were 0-1 aphids/tiller).

Focusing on the medium pest infestation level and keeping the proportion of no-spray fields constant $(0.8 \%)$, with a $10 \%$ increase in the proportion of ET fields in South East England ( $\sigma_{\text {ET }}$ in Eq. 1), the economic surplus value of natural pest control $(\Delta \mathrm{ES})$ would increase by $\sim f 0.4$ Million (average annual value of the peak aphid densities of 2-4 aphids/tiller from 2010 to 2014, with base year 2014) in the region. This equates to an average value increase of $23.4 \%$ (standard deviation 15.6\%) (Fig. 4). This shows that using the ET strategy to control summer grain aphid can positively contribute to the economic benefits provided by natural enemies. 


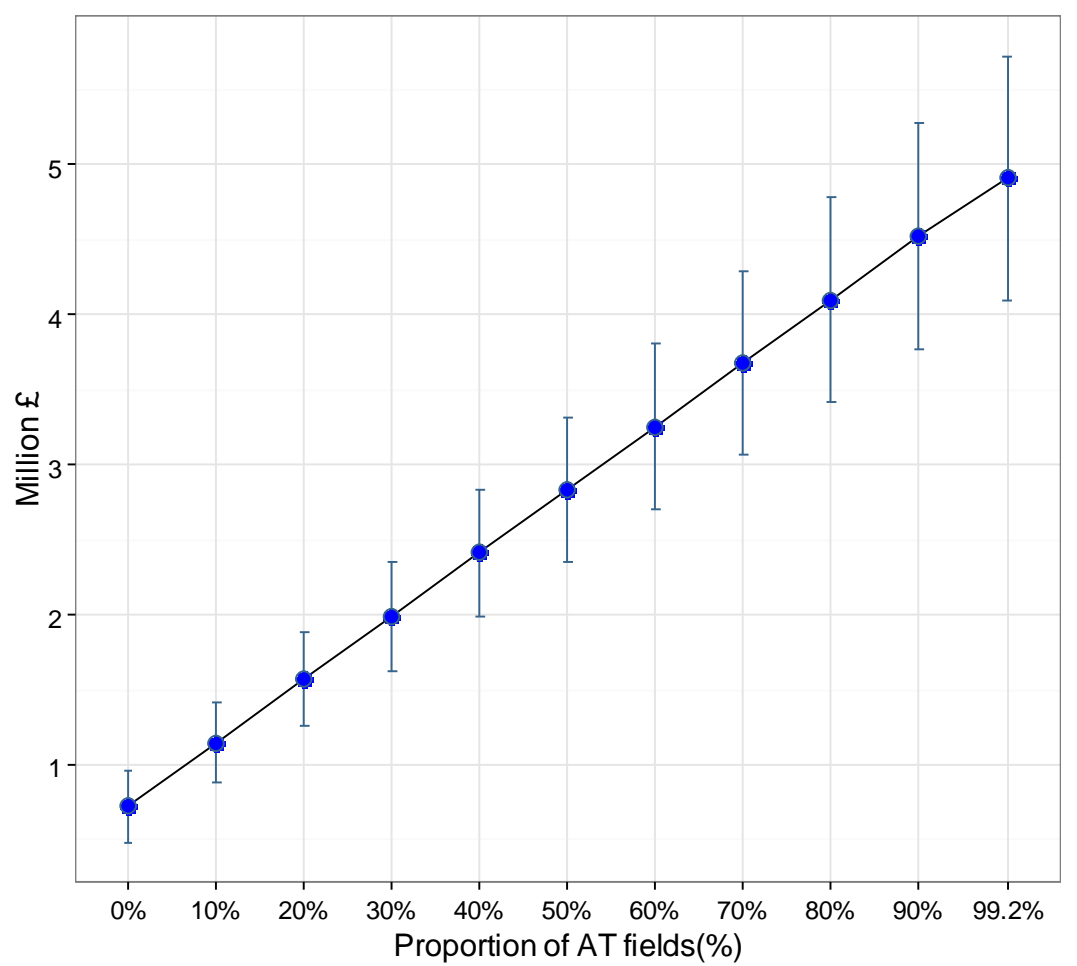

Fig 4. Economic surplus values of natural pest control of summer grain aphid in wheat in South East England with a change in the proportion of economic threshold-based (ET) fields while keeping other indicators constant, under the medium pest infestation level. The blue dots denote average values (Million $f$ ) of peak aphid densities of 2-4 aphids/tiller, from 2010 to 2014 (2014 as base year), and the error bars denote related standard deviations.

The share of benefits that producers (i.e., wheat farmers) would achieve from natural pest control service in their fields is an important consideration in encouraging them to adopt the ET method (Östman et al., 2003). This could be reflected in the proportion of producer surplus (\%PS), which is determined by the price elasticities of supply and demand ( $\varepsilon$ and $\eta$ respectively):

$\% P S=\frac{\Delta P S}{\Delta E S}=\frac{\eta}{\varepsilon+\eta}$

As for consumers (i.e., wheat processing companies that purchase wheat from farmers), because the proportion of surplus they would achieve from natural pest control service is determined by price 
elasticities (1-\%PS; Eq. 7), their benefits would be enhanced with the increasing percentage of ET wheat fields in South East England (Fig. 3 \& 4). Thus consumers would generally benefit from farmers adopting the ET strategy in the fields, unless their share of benefits becomes close to zero (when the absolute value of demand elasticity is close to infinite, i.e., perfect elastic; or supply elasticity is close to zero, perfect inelastic).

Because little information is available on the wheat price elasticities of supply or demand within the UK context, their variations can potentially influence the economic surplus and proportion of producer surplus. Under the ET method, variation in the insecticide input costs (reflected in the IET in Eq. 1) could also influence these values. Thus, for the above mentioned indicators, we conducted a set of sensitivity analyses to compare their influence on the outputs, by decreasing and increasing their current values (see Table 2 ) by $10 \%$ respectively, while keeping other indicators constant (Table 3).

\begin{tabular}{|c|c|c|c|}
\hline$\varepsilon$ & $\eta$ & $\Delta \mathrm{ES}$ (Million $\mathrm{f}$ ) & $\% \mathrm{PS}(\%)$ \\
\hline$-10 \%$ & -- & $2.4(0.4)$ & 73.5 \\
\hline 0.12 & 0.3 & $2.3(0.4)$ & 71.4 \\
\hline$+10 \%$ & -- & $2.2(0.4)$ & 69.4 \\
\hline -- & $-10 \%$ & $2.3(0.4)$ & 69.2 \\
\hline 0.12 & 0.3 & $2.3(0.4)$ & 71.4 \\
\hline-- & $+10 \%$ & $2.3(0.4)$ & 73.3 \\
\hline \multicolumn{2}{|c|}{ Insecticide input ( $\mathrm{f} / \mathrm{ha}$ ) } & $\Delta \mathrm{ES}$ (Million $\mathrm{f}$ ) & $\% \mathrm{PS}(\%)$ \\
\hline \multicolumn{2}{|c|}{$-10 \%$} & $2.1(0.4)$ & 71.4 \\
\hline \multicolumn{2}{|c|}{ Baseline } & $2.3(0.4)$ & 71.4 \\
\hline \multicolumn{2}{|c|}{$+10 \%$} & $2.5(0.4)$ & 71.4 \\
\hline
\end{tabular}

Table 3. Sensitivity analyses of the influence of the price elasticity of supply $(\varepsilon)$, absolute value of price elasticity of demand $(\eta)$, and insecticide costs on the economic surplus $(\Delta E S)$ and proportion of producer surplus (\%PS).

Note: $\Delta \mathrm{ES}$ is the average economic surplus value of peak grain aphid densities of 2-4 aphids/tiller, from 2010 to 2014 (2014 as base year), and the numbers in the brackets denote related standard deviations; for insecticide input, 'Baseline' denotes the respective values from Table 2. 
Keeping other indicators constant, with a $10 \%$ increase in the supply elasticity (from 0.11 to 0.12 , and from 0.12 to 0.13 ), the economic surplus value of natural pest control of summer grain aphid in wheat in South East England would decrease by an average of $4 \%$ (from $f 2.4$ to 2.3 Million, and from f2.3 to 2.2 Million). The proportion of producer surplus would decrease by $3 \%$. On the other hand, a $10 \%$ increase in the absolute value of demand elasticity (from 0.27 to 0.3 , and from 0.3 to 0.33 ) has little influence on the economic surplus, but it would increase the benefit share to producers by $3 \%$. A $10 \%$ increase in the insecticide costs would not influence the proportion of producer surplus, but it would increase the total surplus value by $9 \%$.

\section{Discussion}

By using an economic surplus approach, this study estimated the annual value of natural pest control of the summer grain aphid in wheat in South East England to be f0-2.3 Million, depending on the levels of pest infestation (base year 2014). To our knowledge, this is one of the first attempts to conduct economic evaluation on this ecosystem service within a UK context (Naranjo et al., 2015). It is also among the first studies to estimate the economic contribution of natural pest control on wheat, one of the most widely grown crops in the UK and many other countries (Sandhu et al., 2015). This research only focused on the control of summer grain aphid damage by natural enemies present in the wheat fields. However, the same natural enemies could potentially provide further crop protection by consuming other related pests (e.g., rose - grain aphid, Metopolophium dirhodum) (Dewar et al., 2016; Holland and Oakley, 2007). Thus the economic benefits provided by these natural enemies could potentially by higher.

The lowered monetary value of natural pest control under high pest densities reflected that the economic contribution of this ecosystem service could be limited by the level of pest infestation (Fig. 3). This resulted because, under the high pest infestation level, natural enemies would not be capable of maintaining grain aphid populations below the economic threshold (Fig. 2; Collins et al. 2002; Kobayashi et al. 2011; Gupta et al. 2012). Following a similar hypothesis, Zhang \& Swinton 
(2012) also estimated that the economic value of natural enemies to control the soybean aphid, Aphis glycines Matsumura, in five Midwestern US states would be lower in years with greater pest densities. This model assumed a linear relationship between the peak grain aphid densities with natural enemies in the wheat fields and those without (Eq. 7). However, higher pest densities could potentially increase the probabilities of natural enemies encountering their prey, thus increase the efficacy of natural pest control. Indeed, by conducting field cage experiments, Safarzoda et al. (2014) found that grain aphid in the closed plots (i.e., excluding natural enemies) reached 1-5 aphids/tiller, while in the open plots they remained $<=0.03$ aphids/tiller (as compared to Table 1 ). Thus our study could have adopted a conservative estimate of the crop protection ability of natural enemies, hence a conservative economic surplus value of this ecosystem service.

Under the current UK situation, it could be expected that low and medium grain aphid infestation levels are more common than high level (Dewar et al., 2016; Holland and Oakley, 2007). However, future climate change may increase the inter-annual variation in grain aphid abundance and its related natural enemies, and the predator-prey relationships. Increasing average temperature could have a positive effect on the population growth of grain aphid (Ciss et al., 2014); however, it may also increase the predation rate by related natural enemies (Khan et al., 2016; Sentis et al., 2012). On the other hand, higher precipitation/temperature seasonality may inhibit aphid activities and facilitate natural pest control in the fields (Diehl et al., 2013).

This study illustrated that using an action-threshold (ET) spraying strategy to control grain aphid could enhance the economic benefits provided by natural enemies in wheat fields, which is one of the main aims of integrated pest management (IPM) promoted by the Food and Agriculture Organization of the United Nations (FAO, 2017). The model assumed a near-linear relationship between the proportion of ET wheat fields and value of natural enemies (Fig. 4). However, in a real situation, the increase in the ET fields could potentially enhance the efficiency of natural pest control, due to the reduced disturbance from insecticides in neighbouring fields (Dasgupta et al., 
2007; Furlong et al., 2004). Thus the contribution of the ET method towards the value of natural pest control could potentially be higher.

Little data is available on the adoption rate of ET method for a certain crop-pest system (but see Song \& Swinton 2009). The LEAF (Linking Environment and Farming) Marque is an environmental assurance system recognising sustainably farmed produce, where the certified farm businesses are required to follow a set of nine management principles, including IPM (LEAF, 2016). Similar to 2013, 5\% wheat fields in UK were managed by this system in 2014 (LEAF, 2015). However, from 2013 to 2014, a 10\% increase has been achieved for the total UK croplands grown by these businesses. It is thus reasonable to assume that the proportion of wheat fields using ET strategy to control summer grain aphid has grown beyond $5 \%$ in the UK, and that it has potential to increase.

Under the ET method, the contribution of natural pest control service is also reflected by the related reduction of insecticide input. If insecticide costs become more expensive to control the same level of pest infestation, the economic value of this ecosystem service will increase accordingly (Table 3). Increasing insecticide costs are possible due to the development of insecticide resistance in grain aphid in the UK (Foster et al., 2014), which might require additional spray rounds or higher application rates in the future (Dewar, 2014; Wilson and Tisdell, 2001). This may lead to further increase in the input costs because of the 'pesticide treadmill' (Nicholls and Altieri, 1997). It has been estimated that at least $10 \%$ of pesticides in the US were applied to deal with increasing resistance problems (Pimentel, 2005). Rising chemical costs and the resulting increase in the economic value of natural enemies could justify the growing efforts worldwide to encourage IPM (Böcker and Finger, 2016; Jones et al., 2016; Rasche et al., 2016).

The estimated insecticide costs in this study were a broad estimation (Table 2) and are considered to be conservative. This is because the potential side effects of insecticides toward health, non-target species, and the wider environment have not been fully taken into account (Zhang et al., 2017). For example, due to surface runoff and drift, pyrethroids widely exist in water and especially sediment 
(due to high hydrophobicity), posing significant risks to water column species and benthic invertebrates (Li et al., 2017; Stehle and Schulz, 2015). Indeed, Pimentel (2005) estimated that the total externality costs from pesticides was similar to the investment in pesticide control in the US (about $\$ 10$ billion annually). Thus, if the externality costs of applying pyrethroids to control grain aphid in the study region were considered in the analyses, the economic benefits of natural pest control would have been higher.

Because the price elasticities of supply and demand for wheat could also influence the amount and distribution of economic benefits provided by natural pest control (Table 3; Alston et al. 1998), they should be properly measured for effective decision-making process (Griffith et al., 2001). However, there is little information about these indicators for the UK and its regional markets.

The price elasticity of supply in this study was assumed to be inelastic (Table 2), which was also reflected in previous research (Griffith et al., 2001; Zhuang and Abbott, 2007). As wheat is the most widely grown arable crop in South East England (0.2 million ha, $20.4 \%$ of total farmed area in this region, average from 2010 to 2014) (DEFRA, 2016b, 2016c), farmers would have limited land to increase the percentage of production if wheat price increases (Jansson and Heckelei, 2011). Thus, it is reasonable to assume that supply elasticity in this region is inelastic. As for the price elasticity of demand, because the economic surplus model used in the study follows a closed economy approach and wheat is a staple food, it is also reasonable to assume that consumers' demand is relatively unresponsive to the change in price (Alston et al., 1998; Angus et al., 2009).

However, in reality, wheat is an internationally traded good. Because UK contributes less than $2 \%$ of the total export wheat in the world (Workman, 2017), the wheat market in South East England probably will not influence the international wheat price significantly. Thus, an alternative assumption is a small open economy (Alston et al. 1998, p227). The alternative model is obtained essentially by taking the limit of Eq. 4 as $\eta$ reaches infinity (i.e., perfect elastic). Thus, according to 
the sensitivity analyses (Table 3), the alternative model would result in similar $\Delta \mathrm{ES}$, but all the benefits from natural pest control service would go to wheat farmers.

By using an economic surplus approach, this study not only estimated the economic contribution of natural enemies to wheat protection, but also indicates that there is a financial incentive for farmers to use the economic threshold strategy for pest management. However, this factor alone may not be enough to persuade more farmers to adopt this method. Indeed, farmers' decisions on pest control are influenced by a set of complex factors: e.g., complexity of the related techniques (Shojaei et al., 2013), farmers' perception of risk (Milne et al., 2016; Park et al., 1997), and their environmental awareness (Lefebvre et al., 2015). In order to secure wider adoption of IPM in agricultural production, more studies need to be conducted on farmers' incentives to use these techniques in their fields (Lefebvre et al., 2015). Also, this study only incorporated one aspect of IPM in the evaluation process (i.e., economic threshold). To provide a more comprehensive analysis of the contribution of IPM towards the enhancement of natural pest control service in the croplands, future research should be done to incorporate other related techniques (e.g., providing semi-natural habitats for natural enemies, such as beetle banks). This would require the researchers to measure the monetary inputs and outputs in the field experiments, an area where little data exists (Letourneau et al., 2015).

\section{Conclusion}

With an ecological-economic model, this study assigned monetary values of natural pest control of the summer grain aphid in wheat in South East England. It addressed the limits of natural pest control under the high pest infestation level, and positive contribution of using economic thresholdbased spraying method on the values of this ecosystem service. Because of the development of insecticide resistance in UK grain aphid, the potential subsequent increase in insecticide application 
costs would increase the economic value of natural pest control, and thus the justification of promoting natural enemies in the fields. The price elasticities of supply and demand for wheat could also influence the amount and distribution of the benefits brought by this ecosystem service. Due to various assumptions used in the model, the values derived from this study should be interpreted as conservative estimates. Although this study showed that farmers would benefit from incorporating natural enemies in their pest management decision-makings, more studies need to be conducted on their attitudes and concerns of adopting related conservation techniques in the fields. To have a more comprehensive analysis on the economic value of natural pest control or other ecosystem services in the agricultural sector, more monetary data should be collected from field studies looking at the effectiveness of these measures.

\section{Acknowledgement}

This research received funding from the European Community's Seventh Framework Programme under grant agreement no 311781, LIBERATION Project (LInking farmland Biodiversity to Ecosystem seRvices for effective ecological intensificATION; http://www.fp7liberation.eu/). We sincerely thank Rebecca Evans and Louise Truslove who participated in the natural enemy exclusion experiment used in this study. We sincerely thank Amy W. Ando and Deborah K. Letourneau for their valuable feedback on the manuscript. 


\section{References}

ABC, 2014. The Agricultural Budgeting \& Costing Book, 80th ed. Agro Business Consultants Ltd., Melton Mowbray, UK.

ABC, 2013. The Agricultural Budgeting \& Costing Book, 79th ed. Agro Business Consultants Ltd., Melton Mowbray, UK.

ABC, 2012. The Agricultural Budgeting \& Costing Book, 78th ed. Agro Business Consultants Ltd., Melton Mowbray, UK.

ABC, 2011. The Agricultural Budgeting \& Costing Book, 77th ed. Agro Business Consultants Ltd., Melton Mowbray, UK.

ABC, 2010. The Agricultural Budgeting \& Costing Book, 76th ed. Agro Business Consultants Ltd., Melton Mowbray, UK.

AHDB, 2016a. Chlorpyrifos withdrawal [WWW Document]. Agric. Hortic. Dev. Board. URL https://cereals.ahdb.org.uk/press/2016/may/25/pest-control-guidance-updated-to-reflectchlorpyrifos-losses.aspx (accessed 10.21.16).

AHDB, 2016b. Market data centre: Physical prices [WWW Document]. Agric. Hortic. Dev. Board. URL http://cereals-data.ahdb.org.uk/demand/physical.asp

AHDB, 2015. Controlling aphids and virus diseases in cereals and oilseed rape. Kenilworth,UK.

Alston, J.M., Norton, G.W., Pardey, P.G., 1998. Science Under Scarcity: Principles and Practice for Agricultural Research and Priority Setting. CAB International, Oxon, UK.

Angus, A., Burgess, P.J., Morris, J., Lingard, J., 2009. Agriculture and land use: Demand for and supply of agricultural commodities, characteristics of the farming and food industries, and implications for land use in the UK. Land use policy 26, S230-S242. doi:10.1016/j.landusepol.2009.09.020 
Baker, B.P., Benbrook, C.M., III, E.G., Benbrook, K.L., 2002. Pesticide residues in conventional, integrated pest management (IPM)-grown and organic foods: insights from three US data sets. Food Addit. Contam. 19, 427-446. doi:10.1080/02652030110113799

Böcker, T., Finger, R., 2016. European Pesticide Tax Schemes in Comparison: An Analysis of Experiences and Developments. Sustainability 8, 378. doi:10.3390/su8040378

Braat, L.C., de Groot, R., 2012. The ecosystem services agenda:bridging the worlds of natural science and economics, conservation and development, and public and private policy. Ecosyst. Serv. 1, 4-15. doi:10.1016/j.ecoser.2012.07.011

Briggs, G.G., Elliott, M., Farnham, A.W., Janes, N.F., 1974. Structural aspects of the knockdown of pyrethroid. Pestic. Sci. 5, 643-649. doi:10.1002/ps.2780050516

Ciss, M., Parisey, N., Fournier, G., Taupin, P., Dedryver, C.-A., Pierre, J.-S., 2014. Response of Insect Relative Growth Rate to Temperature and Host-Plant Phenology: Estimation and Validation from Field Data. PLoS One 9, e86825.

Collins, K.., Boatman, N.., Wilcox, A., Holland, J.., Chaney, K., 2002. Influence of beetle banks on cereal aphid predation in winter wheat. Agric. Ecosyst. Environ. 93, 337-350. doi:10.1016/S0167-8809(01)00340-1

Dasgupta, S., Meisner, C., Wheeler, D., 2007. Is Environmentally Friendly Agriculture Less Profitable for Farmers? Evidence on Integrated Pest Management in Bangladesh. Rev. Agric. Econ. 29, 103-118.

DEFRA, 2016a. Organic statistics United Kingdom [WWW Document]. URL http://www.defra.gov.uk/statistics/foodfarm/enviro/organics/

DEFRA, 2016b. Agriculture in the English regions: First estimate for 2015. London, UK.

DEFRA, 2016c. Agriculture in the English regions: Second estimate for 2015. London, UK. 
DEFRA, 2015a. Agriculture in the United Kingdom 2014. London, UK.

DEFRA, 2015b. Farming Statistics Final crop areas, yields, livestock populations and agricultural workforce at June 2015 - United Kingdom. London.

DEFRA, 2014. Agriculture in the United Kingdom 2013. London,UK.

Dewar, A.M., 2014. HGCA project report No. 532: Alternative insecticides to control grain aphids, Sitobion avenae, that are resistant to pyrethroids. Kenilworth,UK.

Dewar, A.M., Ferguson, A., Pell, J.K., Nicholls, C., Watts, J., 2016. Research Review No. 86: A review of pest management in cereals and oilseed rape in the UK. Kenilworth,UK.

Diehl, E., Sereda, E., Wolters, V., Birkhofer, K., 2013. Effects of predator specialization, host plant and climate on biological control of aphids by natural enemies: a meta-analysis. J. Appl. Ecol. 50, 262-270. doi:10.1111/1365-2664.12032

Elliott, M., Janes, N.F., Potter, C., 1978. The Future of Pyrethroids in Insect Control. Annu. Rev. Entomol. 23, 443-469. doi:10.1146/annurev.en.23.010178.002303

Ewald, J.A., Wheatley, C.J., Aebischer, N.J., Moreby, S.J., Duffield, S.J., Crick, H.Q.P., Morecroft, M.B., 2015. Influences of extreme weather, climate and pesticide use on invertebrates in cereal fields over 42 years. Glob. Chang. Biol. 21, 3931-3950. doi:10.1111/gcb.13026

FAO, 2017. Integrated Pest Management [WWW Document]. Food Agric. Organ. United Nations. URL http://www.fao.org/agriculture/crops/thematic-sitemap/theme/pests/ipm/en/ (accessed 1.26.17).

FAPRI, 2016. FAPRI - Elasticity Database [WWW Document]. Food Agric. Policy Res. Inst. URL http://www.fapri.iastate.edu/tools/elasticity.aspx

Florax, R.J.G.M., Travisi, C.M., Nijkamp, P., 2005. A meta-analysis of the willingness to pay for 
reductions in pesticide risk exposure. Eur. Rev. Agric. Econ. 32, 441-467.

doi:10.1093/erae/jbi025

Foster, S.P., Paul, V.L., Slater, R., Warren, A., Denholm, I., Field, L.M., Williamson, M.S., 2014. A mutation (L1014F) in the voltage-gated sodium channel of the grain aphid, Sitobion avenae, is associated with resistance to pyrethroid insecticides. Pest Manag. Sci. 70, 1249-1253. doi:10.1002/ps.3683

Furlong, M.J., Shi, Z., Liu, S.-S., Zalucki, M.P., 2004. Evaluation of the impact of natural enemies on Plutella xylostella L. (Lepidoptera: Yponomeutidae) populations on commercial Brassica farms. Agric. For. Entomol. 6, 311-322. doi:10.1111/j.1461-9555.2004.00228.x

Garthwaite, D.G., Barker, I., Laybourn, R., Huntly, A., Parrish, G., Hudson, S., Thygesen, H., 2014. Pesticide Usage Survey Report 263. Arable Crops in the United Kingdom 2014. York.

Garthwaite, D.G., Barker, I., Parrish, G., Smith, L., Chippindale, C., Pietravalle, S., 2010. Pesticide Usage Survey Report 235. Arable Crops in the United Kingdom 2010. York.

Garthwaite, D.G., Hudson, S., Barker, I., Parrish, G., Smith, L., Pietravalle, S., 2012. Pesticide Usage Survey Report 250. Arable Crops in the United Kingdom 2012. London,UK.

Geiger, F., Bengtsson, J., Berendse, F., Weisser, W.W., Emmerson, M., Morales, M.B., Ceryngier, P., Liira, J., Tscharntke, T., Winqvist, C., Eggers, S., Bommarco, R., Pärt, T., Bretagnolle, V., Plantegenest, M., Clement, L.W., Dennis, C., Palmer, C., Oñate, J.J., Guerrero, I., Hawro, V., Aavikh, T., Thies, C., Flohre, A., Hanke, S., Fischer, C., Goedhart, P.W., Inchausti, P., 2010. Persistent negative effects of pesticides on biodiversity and biological control potential on European farmland. Basic Appl. Ecol. 11, 97-105. doi:http://dx.doi.org/10.1016/j.baae.2009.12.001

George, K.S., Gair, R., 1979. Crop loss assessment on winter wheat attacked by the grain aphid, 
Sitobion avenae, (F.), 1974-77. Plant Pathol. 28, 143-149.

Griffith, G., I'Anson, K., Hill, D., Vere, D., 2001. Economic Research Report No. 6: Previous Supply Elasticity Estimates For Australian Broadacre Agriculture. Orange, Australia.

Gupta, R.K., Pervez, A., Guroo, M.A., Srivastava, K., 2012. Stage-specific functional response of an aphidophagous ladybird, Coccinella septempunctata (Coleoptera: Coccinellidae), to two aphid species. Int. J. Trop. Insect Sci. 32, 136-141. doi:10.1017/S1742758412000227

Haile, M.G., Kalkuhl, M., von Braun, J., 2015. Worldwide Acreage and Yield Response to International Price Change and Volatility: A Dynamic Panel Data Analysis for Wheat, Rice, Corn, and Soybeans. Am. J. Agric. Econ. 98, 172-190. doi:10.1093/ajae/aav013

Holland, J.M., 2004. The environmental consequences of adopting conservation tillage in Europe: reviewing the evidence. Agric. Ecosyst. Environ. 103, 1-25. doi:10.1016/j.agee.2003.12.018

Holland, J.M., Oakley, J., 2007. Research Review No. 64: Importance of arthropod pests and their natural enemies in relation to recent farming practice changes in the UK. Kenilworth,UK.

Jansson, T., Heckelei, T., 2011. Estimating a Primal Model of Regional Crop Supply in the European Union. J. Agric. Econ. 62, 137-152. doi:10.1111/j.1477-9552.2010.00270.x

Jones, V.P., Mills, N.J., Brunner, J.F., Horton, D.R., Beers, E.H., Unruh, T.R., Shearer, P.W., Goldberger, J.R., Castagnoli, S., Lehrer, N., Milickzy, E., Steffan, S.A., Amarasekare, K.G., Chambers, U., Gadino, A.N., Gallardo, R.K., Jones, W.E., 2016. From planning to execution to the future: An overview of a concerted effort to enhance biological control in apple, pear, and walnut orchards in the western U.S. Biol. Control 102, 1-6. doi:10.1016/j.biocontrol.2016.03.013

Khan, M.A.Z., Liang, Q., Maria, M.S.M., Liu, T.-X., 2016. Effect of Temperature on Functional Response of Aphidius gifuensis (Hymenoptera: Braconidae) Parasitizing Myzus persicae (Hemiptera: Aphididae). Florida Entomol. 99, 696-702. doi:10.1653/024.099.0419 
Kobayashi, T., Takada, M., Takagi, S., Yoshioka, A., Washitani, I., 2011. Spider predation on a mirid pest in Japanese rice fields. Basic Appl. Ecol. 12, 532-539. doi:10.1016/j.baae.2011.07.007

Larsson, H., 2005. A crop loss model and economic thresholds for the grain aphid, Sitobion avenae (F.), in winter wheat in southern Sweden. Crop Prot. 24, 397-405.

LEAF, 2016. LEAF Marque Standard version 14.0. Stoneleigh Park, Warwickshire.

LEAF, 2015. A review of our 2014 global impacts. Stoneleigh Park, Warwickshire.

Lefebvre, M., Langrell, S.R.H., Gomez-y-Paloma, S., 2015. Incentives and policies for integrated pest management in Europe: a review. Agron. Sustain. Dev. 35, 27-45. doi:10.1007/s13593-014$0237-2$

Letourneau, D.K., Ando, A.W., Jedlicka, J.A., Narwani, A., Barbier, E., 2015. Simple-but-sound methods for estimating the value of changes in biodiversity for biological pest control in agriculture. Ecol. Econ. 120, 215-225. doi:http://dx.doi.org/10.1016/j.ecolecon.2015.10.015

Li, H., Cheng, F., Wei, Y., Lydy, M.J., You, J., 2017. Global occurrence of pyrethroid insecticides in sediment and the associated toxicological effects on benthic invertebrates: An overview. J. Hazard. Mater. 324, 258-271. doi:10.1016/j.jhazmat.2016.10.056

Liu, X., Chen, M., Collins, H.L., Onstad, D.W., Roush, R.T., Zhang, Q., Earle, E.D., Shelton, A.M., 2014. Natural Enemies Delay Insect Resistance to Bt Crops. PLoS One 9, e90366.

Martin, E.A., Reineking, B., Seo, B., Steffan-Dewenter, I., 2013. Natural enemy interactions constrain pest control in complex agricultural landscapes. Proc. Natl. Acad. Sci. 110, 5534-5539. doi:10.1073/pnas.1215725110

Milne, A.E., Bell, J.R., Hutchison, W.D., van den Bosch, F., Mitchell, P.D., Crowder, D., Parnell, S., Whitmore, A.P., 2016. The Effect of Farmers' Decisions on Pest Control with Bt Crops: A Billion Dollar Game of Strategy. PLOS Comput. Biol. 11, 1-18. doi:10.1371/journal.pcbi.1004483 
Naranjo, S.E., Ellsworth, P.C., Frisvold, G.B., 2015. Economic Value of Biological Control in Integrated Pest Management of Managed Plant Systems. Annu. Rev. Entomol. 60, 621-645. doi:10.1146/annurev-ento-010814-021005

Nicholls, C.I., Altieri, M.A., 1997. Conventional agricultural development models and the persistence of the pesticide treadmill in Latin America. Int. J. Sustain. Dev. World Ecol. 4, 93-111. doi:10.1080/13504509709469946

Nix, J., 2014. John Nix Farm management pocketbook, 44th ed. Agro Business Consultants Ltd., Melton Mowbray, UK.

Nix, J., 2013. John Nix Farm management pocketbook, 43rd ed. Agro Business Consultants Ltd., Melton Mowbray, UK.

Nix, J., 2012. John Nix Farm management pocketbook, 42nd ed. Agro Business Consultants Ltd., Melton Mowbray, UK.

Nix, J., 2011. John Nix Farm management pocketbook, 41st ed. Agro Business Consultants Ltd., Melton Mowbray, UK. doi:9780951458877

Nix, J., 2010. The John Nix Farm Management Pocketbook, 40th ed. The Andersons Centre, Melton Mowbray, UK.

Oakley, J.N., Walters, K.F.A., 1994. A field evaluation of different criteria for determiningthe need to treat winter wheat against the grain aphid Sitobion avenae and the rose-grain aphid Metopolophium dirhodum. Ann. Appl. Biol. 124, 195-211. doi:10.1111/j.17447348.1994.tb04128.x

ONS, 2016. Time series: CPI All Items Index: Estimated pre-97 2015=100 [WWW Document]. Off. Natl. Stat. URL https://www.ons.gov.uk/economy/inflationandpriceindices/timeseries/d7bt/mm23 (accessed 
9.2.16).

Östman, Ö., Ekbom, B., Bengtsson, J., 2003. Yield increase attributable to aphid predation by groundliving polyphagous natural enemies in spring barley in Sweden. Ecol. Econ. 45, 149-158.

Park, J., Farmer, D.P., Bailey, A.P., Keatinge, J.D.H., Rehman, T., Tranter, R.B., 1997. Integrated Arable Farming Systems and their potential uptake in the UK. Farm Manag. 9, 483-494.

Pedigo, L.P., Hutchins, S.H., Higley, L.G., 1986. Economic Injury Levels in Theory and Practice. Annu. Rev. Entomol. 31, 341-368. doi:10.1146/annurev.en.31.010186.002013

Pimentel, D., 2005. Environmental and Economic Costs of the Application of Pesticides Primarily in the United States. Environ. Dev. Sustain. 7, 229-252. doi:10.1007/s10668-005-7314-2

Plantegenest, M., Pierre, J.S., Dedryver, C.A., Kindlmann, P., 2001. Assessment of the relative impact of different natural enemies on population dynamics of the grain aphid Sitobion avenae in the field. Ecol. Entomol. 26, 404-410. doi:10.1046/j.1365-2311.2001.00330.x

Porter, J., Costanza, R., Sandhu, H., Sigsgaard, L., Wratten, S., 2009. The Value of Producing Food, Energy, and Ecosystem Services within an Agro-Ecosystem. AMBIO A J. Hum. Environ. 38, 186193. doi:10.1579/0044-7447-38.4.186

Potts, S.G., Imperatriz-Fonseca, V., Ngo, H.T., Aizen, M.A., Biesmeijer, J.C., Breeze, T.D., Dicks, L. V, Garibaldi, L.A., Hill, R., Settele, J., Vanbergen, A.J., 2016. Safeguarding pollinators and their values to human well-being. Nature 540, 220-229.

Ramsden, M.W., Kendall, S.L., Ellis, S.A., Berry, P.M., 2017. A review of economic thresholds for invertebrate pests in UK arable crops. Crop Prot. doi:10.1016/j.cropro.2017.01.009

Rasche, L., Dietl, A., Shakhramanyan, N., Pandey, D., Schneider, U.A., 2016. Increasing social welfare by taxing pesticide externalities in the Indian cotton sector. Pest Manag. Sci. 72, 2303-2312. doi:10.1002/ps.4275 
Roubos, C.R., Rodriguez-Saona, C., Isaacs, R., 2014. Mitigating the effects of insecticides on arthropod biological control at field and landscape scales. Biol. Control 75, 28-38. doi:10.1016/j.biocontrol.2014.01.006

Rusch, A., Bommarco, R., Jonsson, M., Smith, H.G., Ekbom, B., 2013. Flow and stability of natural pest control services depend on complexity and crop rotation at the landscape scale. J. Appl. Ecol. 50, 345-354.

Safarzoda, S., Bahlai, C.A., Fox, A.F., Landis, D.A., 2014. The role of natural enemy foraging guilds in controlling cereal aphids in Michigan wheat. PLoS One 9, e114230. doi:10.1371/journal.pone.0114230

Sandhu, H., Wratten, S., Costanza, R., Pretty, J., Porter, J.R., Reganold, J., 2015. Significance and value of non-traded ecosystem services on farmland. PeerJ 3, e762. doi:http://dx.doi.org/10.7717/peerj.762

Schaefer, M., Goldman, E., Bartuska, A.M., Sutton-Grier, A., Lubchenco, J., 2015. Nature as capital: Advancing and incorporating ecosystem services in United States federal policies and programs. Proc. Natl. Acad. Sci. U. S. A. 112, 7383-7389. doi:10.1073/pnas.1420500112

Schmidt, M.H., Lauer, A., Purtauf, T., Thies, C., Schaefer, M., Tscharntke, T., 2003. Relative importance of predators and parasitoids for cereal aphid control. Proc. R. Soc. B Biol. Sci. 270, 1905-1909.

Sentis, A., Hemptinne, J.-L., Brodeur, J., 2012. Using functional response modeling to investigate the effect of temperature on predator feeding rate and energetic efficiency. Oecologia 169, 11171125.

Shojaei, S.H., Hosseini, S.J.F., Mirdamadi, M., Zamanizadeh, H.R., 2013. Investigating barriers to adoption of integrated pest management technologies in Iran. Ann. Biol. Res. 4, 39-42. 
Song, F., Swinton, S.M., 2009. Returns to Integrated Pest Management Research and Outreach for Soybean Aphid. J. Econ. Entomol. 102, 2116-2125.

Stehle, S., Schulz, R., 2015. Agricultural insecticides threaten surface waters at the global scale. Proc. Natl. Acad. Sci. 112, 5750-5755. doi:10.1073/pnas.1500232112

Stern, V., Smith, R., van den Bosch, R., Hagen, K., 1959. The integration of chemical and biological control of the spotted alfalfa aphid: The integrated control concept. Hilgardia 29, 81-101. doi:10.3733/hilg.v29n02p081

Thies, C., Haenke, S., Scherber, C., Bengtsson, J., Bommarco, R., Clement, L.W., Piotr, C., Dennis, C., Emmerson, M., Gagic, V., Hawro, V., Jaan, L., Weisser, W.W., Winqvist, C., Tscharntke, T., 2011. The relationship between agricultural intensification and biological control:experimental tests across Europe. Ecol. Appl. 21, 2187-2196.

Wilson, C., Tisdell, C., 2001. Why farmers continue to use pesticides despite environmental, health and sustainability costs. Ecol. Econ. 39, 449-462.

Workman, D., 2017. Wheat Exports by Country [WWW Document]. World's Top Export. URL http://www.worldstopexports.com/wheat-exports-country/ (accessed 11.13.17).

Zhang, H., Breeze, T., Bailey, A., Garthwaite, D., Harrington, R., Potts, S.G., 2017. Arthropod Pest Control for UK Oilseed Rape - Comparing Insecticide Efficacies, Side Effects and Alternatives. PLoS One 12, e0169475.

Zhang, W., Swinton, S.M., 2012. Optimal control of soybean aphid in the presence of natural enemies and the implied value of their ecosystem services. J. Environ. Manage. 96, 7-16. doi:10.1016/j.jenvman.2011.10.008

Zhuang, R., Abbott, P., 2007. Price elasticities of key agricultural commodities in China. China Econ. Rev. 18, 155-169. doi:10.1016/j.chieco.2006.02.006 